\title{
Common Ground: Comparative Histories of Cinema Audiences
}

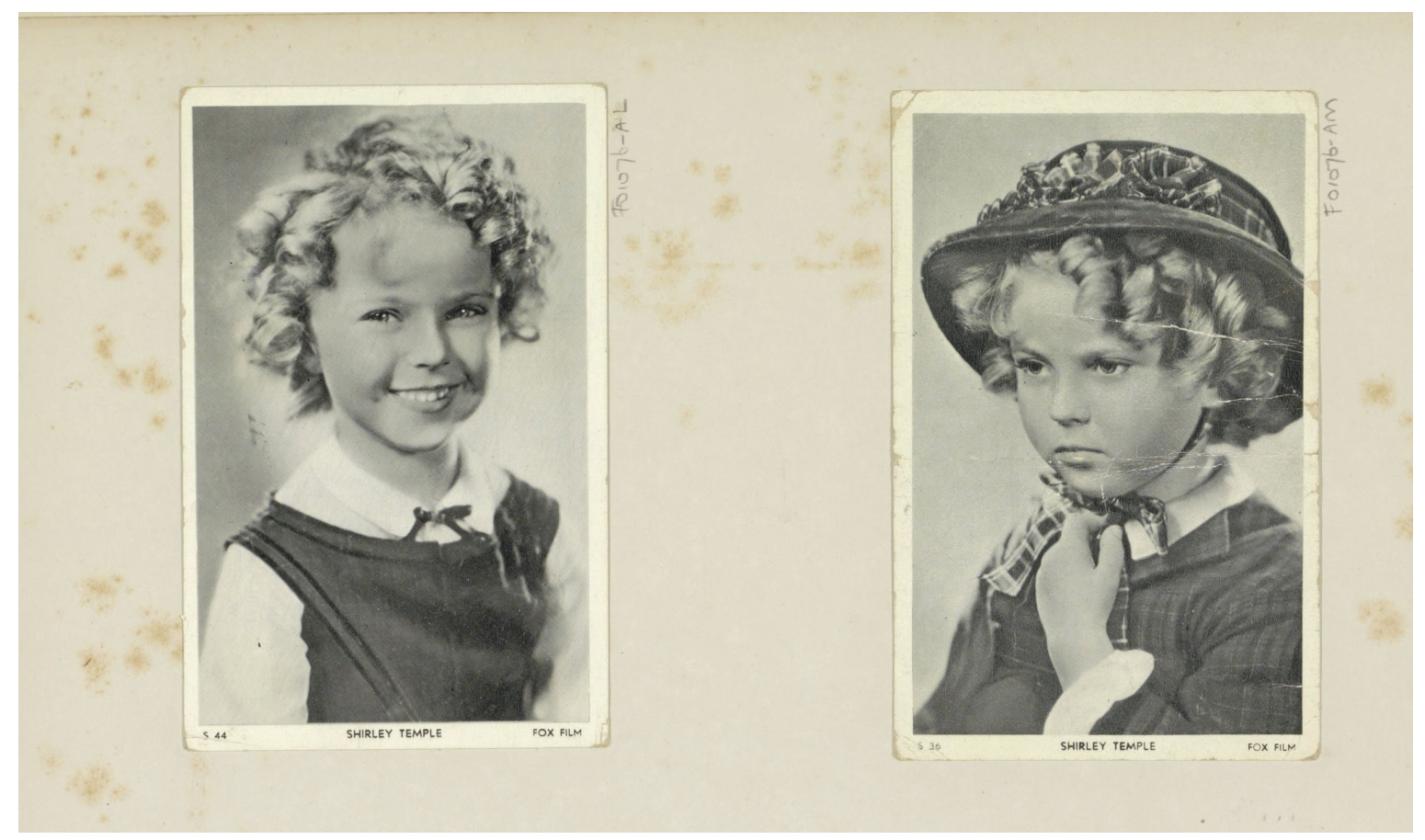

Portrait of Shirley Temple as a child, Fox Film. From a collector's album. Rijksmuseum, http://hdl.handle.net/10934/RM0001.COLLECT.269434.

\section{Comparative cinema histories}

In 2006, when the 'spirit of New Cinema History' was materialising, Richard Maltby called for a cinema history from below, in contrast to a film historiography that started (and usually ended) with films and their directors. Instead, he pleaded for scholars to turn their attention to film audiences and the social and societal impact of cinema. ${ }^{1}$ To attain this goal, Maltby argued that a different methodology would need to be adopted in contrast with the traditional textual analysis tool kit mostly derived from literary 
studies. He advocated methods that borrowed both from historiography at large - as had been the clarion call of New Film History, emblematised by Allen and Gomery's Film History in 1985 - but also approaches that traditionally stem from the realm of the social sciences (even if historians and other humanists have also appropriated them extensively), such as economics, demographics, geography and other disciplines with quantitative and/or statistical traditions. The occasion of the 2006 special issue of Tijdschrift voor Mediageschiedenis (as TMG Journal for Media History was then still called) where Maltby's article appeared, was the launch of the Cinema Context database, an exemplary symbol of the data driven pillar that has become characteristic of New Cinema History. In Maltby's plea, quantitative data like that stored in Cinema Context could be used for detailed maps of cinema culture. However, cinema-specific data would always need contextualisation through correlation to knowledge not directly related to cinema such as demographic and socio-economic information. Looking back, it appears that the first part of Maltby's call may have been followed more extensively than the second exhortation to involve the non-cinematic.

Maltby cautioned that these 'quantitative generalisations' needed to be grounded in specific, localised experiences, in the form of microhistories à la Ginzburg's The Cheese and the Worms that situate an idiosyncratic, individually appropriated world view within a wider media landscape, mutually enriching our understanding of both the nearby local and the global, a sensibility that is echoed in Jeff Klenotic's use of the term 'splatial' in his essay in the current collection. Maltby closes his article with the following sentences, looking towards the future of New Cinema History:

One of these microhistories may become the Montaillou of cinema history, through what it may reveal about how its citizen consumers explained themselves and their place in the world through their encounters with the forces of global and globalising culture. Such histories, self-consciously acknowledging their own constructions and mediations, may also form part of comparative local histories, and, finally, may underpin attempts to consider the cultural function and performance of individual movies in more secure social and cultural detail than we can presently achieve. ${ }^{2}$

Maltby foregrounds 'comparative local histories' as one of the steps towards realising perhaps the ultimate ambition of New Cinema History, which is to 'close the circle' and arrive back to addressing 
the meanings and agencies of specific films. Since 2006, the body of work accomplished in the field of New Cinema History is impressive. Even if the 'Montaillou of cinema history' is ostensibly still waiting for its Le Roy Ladurie, there certainly has been a growth of interest in comparative histories in the field and the goal of this special issue is to take stock of that scholarly activity.

The wish to combine wide-ranging approaches with localised ones, or, in a reduction of Maltby's more nuanced plea, to combine the quantitative with the qualitative, points to a variation within the interdisciplinary space that New Cinema History occupies, that ranges from orientations towards finding regularities, patterns and generalisations, and on the other side of the spectrum, a gravitation towards the local case study, the singular, the microstoria. Stefan Berger distinguishes between individualising and universalising comparisons. ${ }^{3}$ The former sets 'out to demonstrate the uniqueness of one particular case,' using a comparison to other cases to better comprehend that single case. Universalising comparisons tend to prioritise similarities between cases and usually provides a more equal weight to all of the cases involved.

Acknowledging this distinction, Daniel Bilteryest and Philippe Meers have proposed that we loosen up our thinking about comparative research: beside the classic research setup where one employs a single methodological framework on a range of (geographical) entities to be compared, they point out that other, less systematic comparative analysis can also yield worthwhile results. Even if there is no rigorous hypothesis testing involved, juxtaposing divergent methodological approaches to a similar problem can have an hermeneutic value, offering researchers new ideas, helping to create new hypotheses and stimulating multiperspectivity. ${ }^{4}$

The editors of this collection have adopted this hospitable, broad-tent interpretation of comparative cinema history. The reader will find studies positioned across the spectrum: ranging from the 'classical' systematic comparison between various localities focused on clearly defined units of comparison to the more intuitive and loosely defined objects of analysis using a comparative sensibility to get a deeper understanding of an individual case, viewed in a wider constellation of comparable cases. Also, it welcomes critical reflections on the comparative approach, such as Jeff Klenotic's warning that reifying a 'higher' level of comparative sophistication can stimulate a false idea of advancement; or Fuhrmann's endorsement of histoire croisée, an approach originally formulated as a critical response addressing overly reductive national comparative frameworks. In addition, Jonathan Petrychyn draws attention to New Cinema History's lack of knowledge of hidden cinemagoing practices and microhistories of queer audiences, who have mostly been left out of 
current historical-empirical audience research. Others in the collection, such as Jessica Whitehead, James Burns, Åsa Jernudd and Mats Lundmark, as well as Aydın Çam and İlke Şanlıer Yüksel continue to critique the overall concentration on (Western) urban centres within New Cinema History, and advocate for the inclusion of rural audiences in comparative cinema histories.

\section{Methods}

The same way a comparison entails finding common ground between entities, however disparate or divergent, New Cinema History as a scholarly community provides common ground in the 'nebula' of diverse methods and approaches that are deployed to scrutinise the social and cultural meanings of moviegoing. One could argue that scholarly practice in New Cinema History finds much more solid ground in methodological engrossment than in theoretical contemplations. This methodological heterogeneity is reflected in the wide range of approaches collected here, covering terrains such as programming analysis, mapping, oral history and cross-media approaches.

Four contributions focus on the analysis of film programming, but each concentrates on different aspects. John Sedgwick looks back on the development of the POPSTAT method that he initiated over 25 years ago, which turned out to be a seminal instrument for measuring and thinking about the popularity of films in cases where we do not possess detailed records about the (economic) performance of individual films. In this contribution, Sedgwick offers his thoughts on how to measure the relative popularity (relPOP) when engaged in comparative research.

A twin pair of articles in the collection uses programming analysis not to lift out significant films, but to find patterns in programming to analyse the workings of urban cinema exhibition. Terézia Porubčanská, Philippe Meers and Daniel Biltereyst juxtapose the cities of Brno (Czech Republic) and Ghent (Belgium) with the question how to appropriately visualise the spatial characteristics of movie exhibition. The authors offer various options: multi-layered mapping, network analysis, and tabular representations that together shed new light on the structure of the exhibition markets in two different European cities, and help to explain differences (but also the remarkable similarities) in their spatial configuration and hierarchical organisation.

A second article that addresses a similar approach (and likewise includes maps, network visualisations, and tabular timelines), compares the film exhibition infrastructure in three European port cities: Antwerp (Belgium), Gothenburg (Sweden) and Rotterdam (Netherlands). By analysing the 
flow of film through these cities, Clara Pafort-Overduin, Kathleen Lotze, Åsa Jernudd and Thunnis van Oort offer new perspectives on film circulation within the individual urban systems and on the relationships between cinemas, and also point to the lack of uniformity of these systems among European cities, a finding also supported by Porubčanská et al.

A fourth contribution that uses programming analysis is Jessica Whitehead's research on the circulation of films during the silent era in the vast Canadian territory. By tracing their national release dates, Whitehead's research shows that the best-selling films of the 1910s and 1920s premiered in an assortment of large Canadian cities, suggesting a lack of centralisation in the national distribution system. Put against this background of national release patterns, Whitehead displays the local peculiarities of film programming in the small industrial town of Timmins.

Although several articles include maps, three contributions have mapping and spatiality as their main methodological concern. We’ve already mentioned Porubčanská et al., who investigate how ambiguous and imprecise information can be visualised geographically and also how maps can be used for new knowledge on the way cinemas were clustered within the urban landscape. A second contribution to utilise mapping is from Åsa Jernudd and Mats Lundmark who plot cinemas in the post-industrial region of Bergslagen to showcase their spatial distribution, and how that relates to parameters such as cinema ownership structure, size and degree of rurality of the community where the cinema was located. Additionally, Jeff Klenonic's piece suggests that New Cinema History is inherently cartographical with scholars constructing ‘deep mapping’ of cinema-going experience through case studies, investigating programming flows and distribution circuits, comparative studies, and collections of oral histories. Klenotic provides a profound reflection on how place and space are in a continuous state of flux and open-endedness.

Investigating the memories of moviegoing via historical interviews or questionnaires has been elemental for the emergence of New Cinema History as a field, decentring the film text in favour of an appreciation of cinema grounded in everyday social and cultural experience. In this collection, several contributions are dedicated to oral history as a method. Pierluigi Ercole, Lies Van de Vijver and Daniela Treveri Gennari reflect on the challenges of oral history research beyond national and linguistic barriers, in order to 'develop a truly comparative analysis on the experience of cinemagoing in Europe.' They argue that a careful balance between local specificity and comparability depends in part on the flexibility of the research team to alternate between a capacity to understand local context and the ability to abstract common grounds for comparison. 
Aydın Çam and İlke Şanlıer Yüksel's lively portrait of cinema culture in the Turkish Taurus highlands during the 1960s and 1970s is primarily based on oral testimonies. The authors aim at correcting the existing historiography on Turkish moviegoing that has so far mostly relied on the metropolitan experience. This regional case study gives cause to take a fresh look at the extant assumptions about moviegoing in urban Turkey, and how they contrast to the rural, in terms of programming, of the social composition of the audience and of the cultural meanings attached to moviegoing.

A third contribution that follows an ethnographic approach, partly based on oral historiography but also on scholarship working from a wider range of sources, is Jacqueline Maingard's analysis of how the cinematic archetype of the cowboy figure resonated across the African continent, in various cultural practices, such as clothing style, dance, or political discourse and censorship.

The variety of methodological traditions converging within New Cinema History also includes an eagerness to cross disciplinary boundaries within media studies. Grietje Hoogland demonstrates how the distribution of Dutch animated films followed distinctively different paths in the theatrical circuit on the one hand and for television on the other, tracks that remained remarkably divided. Hoogland takes an institutional point of view looking at government policy and the characteristics of distribution environments such as film festivals, the $16 \mathrm{~mm}$ circuit, film exhibition in the art museum and television broadcasting, and how the careers of Dutch animated film makers evolved within those habitats.

Lisa Rabin focuses on the non-theatrical circulation of educational film, a familiar topic on the New Cinema History agenda. Rabin's study of Julien Bryan's work uses a wide range of sources to intersect between research of film exhibition, distribution and production, the historiography of audiovisual educational methods in service of an analysis of soft power and politico-cultural relations. Rabin traces how Bryan's short films on Latin America flowed through various circuits, and how the films were appropriated by teachers, art historians and activists along a spectrum of ideological perspectives on Pan-Hemispheric relations in the US.

A third example is Jonathan Petrychyn's plea for a stronger interaction between New Cinema History and film festival studies. He argues that both subfields cover similar terrains and would profit from a closer exchange of knowledge. He subsequently posits that such an exchange could help remedy New Cinema History's alleged inattentiveness to the cinema practices of marginalized communities, in his case exemplified by a study of affective practices surrounding queer film festivals. 


\section{Themes}

Besides a diversity in methods, this collection also showcases a broad thematic range, covering a wide array of periods, localities and subject matters. In this section we want to briefly reflect on the most prominent themes that have emerged.

One of the key themes in this collection, which also grapples with the existing tradition within New Cinema History, is the exploration of how people in rural areas experienced cinema differently from their urban counterparts. ${ }^{5}$ Four pieces reflect on rural cinema-going, two in former colonies of Great Britain such as Jessica Whitehead's piece exploring distribution patterns between rural and urban locations in Canada and James Burns' piece looking at former British colonies in the British West Indies. In addition, Åsa Jernudd and Mats Lundmark explore rural cinema-going in Sweden and Aydın Çam and İlke Şanlıer Yüksel examine rural cinemas in Turkey. It emerges from these pieces that many rural communities could produce highly particular cinema cultures. For example, we learn in Åsa Jernudd and Mats Lundmark's article that in Sweden, rural cinemas in the region of Bergslagen were often tied to workers and other grassroots movements. Çam and Yüksel outline how open air and informal exhibition spaces were more prevalent in Turkey's rural areas and they also explore the distinctive nature of audience participation during screenings in these areas.

The collection adds to the literature on rural cinema-going through embracing comparative methodologies. By comparing rural exhibition to urban centres Jessica Whitehead, Aydın Çam and İlke Şanlıer Yüksel, and James Burns all outline how distribution and exhibition practices varied greatly throughout different rural regions. James Burns in fact highlights in his research on the British West Indies, that Jamaica despite having a much larger population had fewer theatres because of a lack of rural exhibition when compared to Trinidad which had more rural theatres that catered to immigrant South Asian audiences.

Opening up New Cinema History to different perspectives and ideas of intersectionality in terms of audience and exhibition research was a goal of this collection. James Burns' sweeping overview of British-Caribbean cinema cultures points to the promising research potential of comparing experiences of moviegoing among the British Indies, with other Caribbean communities and with other (British) colonial territories. Burns' article is one of several pieces examining nonwestern locations such as Aydın Çam and İlke Şanlıer Yüksel with their focus on Turkey, Jacqeline 
Maingard on the appropriations of the cowboy figure throughout countries in Africa, and Lisa Rabin on the use of educational film on Latin America in its northerly neighbour the United States. Additionally, Emiel Martens explores in his contribution the relation between tourism, film and empire in Jamaica by analysing in vibrant detail the Fox production of A Daughter of the Gods (1916) that was shot on location in the British colony. Martens analyses how colonial ideology and an eroticised exoticism were inscribed into the production. For the island's promotors of tourism, the promise of the big budget Hollywood circus that had briefly been visited upon the island appeared to be somewhat disappointing, because when the final product was released it turned out that the specifics of the Jamaican location had blended into a generalised tropical décor.

In another example of filmic exchange as a key to understand cultural and political relations between countries, Wolfgang Fuhrmann examines how the diplomatic ties between Brazil and Germany were affected by the film Der Weg nach Rio/Road to Rio (1931). The film's depiction of Brazil as the global centre of 'white slavery', even if it was never screened in Brazil, led to a chain of events that had serious political ramifications and closed the Brazilian market for German films for a number of years. Fuhrmann seizes on this case study to argue for practicing entangled history, a form of transnational history that, instead of comparing between geographical areas, analyses interactions between them: 'Crossing and intercrossing have effects and repercussions; they can cause transformations and are based on reciprocity and asymmetry.' (p. 5) Moreover, Jonathan Petrychyn provocatively argues for a closer focus on queer perspectives in conducting New Cinema History research. What emerges from these articles is a clear expansion on what has traditionally been considered New Cinema History and helps to broaden shared research methodologies and questions to geographic regions across the globe.

\section{Moving Forward}

Many of the contributions have been collected from participants in the History of Moviegoing, Exhibition, and Reception (HoMER) conferences. In 2017, the conference was held in Toronto, which was the largest HoMER gathering to date and attracted scholars from all over the globe who were not only researching historical film audiences and exhibition practices, but were also investigating television, digital applications, and film festivals. Since Toronto, the HoMER network has continued 
to expand with meetings in Amsterdam and Nassau, which continued to attract new international scholars as well as interrogate what it means to do 'New Cinema History'.

In publishing this special issue, we hope to help stimulate further global collaborative projects. As was vividly chronicled in Jeff Klenotic's contribution, the collaborative nature of the New Cinema History movement is a defining feature, which is another reason that so many comparative projects are coming to fruition. Particularly we have seen this in recent years with research projects such as those led by Daniela Treveri Gennari (Italian Cinema Audience and European Cinema Audience) as well as Daniel Biltereyst and Philippe Meers (e.g., DICIS and CINECOS). Our collection showcases many of these collaborations and also calls for further international contributions.

In this special issue we advocate the expanded use of comparative approaches, even if we remain cognizant of the tremendous significance of research that does not prioritise such a perspective. As Jeff Klenotic states in his contribution, microhistories continue to be crucial to the larger aims of New Cinema History, and we fully endorse his caution against standardising methodologies that would bring the risk of skewing research towards more easily documented cases. We hope that debates like these, on the merits but also limits of comparative approaches, will enable further flourishing of the field.

Besides the regular peer-reviewed articles, we also welcomed non-peer reviewed contributions in this collection from John Sedgwick and Jacqueline Maingard. For this section, we invited Daniel Biltereyst and Philippe Meers to reflect on the special issue as a whole, in recognition of their earlier work on the topic. As you might notice, their Alphaville article, 'New Cinema History and the Comparative Mode' was referenced by most authors in the collection. We hope that their response to the wide range of contributions stimulates an ongoing debate on the merits and limitations of comparative cinema history.

In sum, we see this collection as a means to continue the New Cinema History project and expand it to include both new localities as well as new perspectives. By opening up the field to new research and researchers, we see this collection as an important continuum to the HoMER experiment and we are excited to see calls for new edited collections in comparative cinema histories. Although it remains to be seen when we can have the next in-person HoMER conference, with the continued threat of COVID-19, we hope this collection sparks new (digital) conversations 
and debates on the directions of New Cinema History, and how we can foster continued comparative and collaborative projects.

Outside of the themed section of this issue of TMG Journal of Media History, Gertjan Willems presents a wide-ranging “In Memoriam” (written in Dutch) of the inimitable Flemish filmmaker and cinematic animal Robbe De Hert, that offers a fascinating impression of the Flemish film climate since the 1960s.

We would like to thank all of the authors and also particularly our peers that have spent time and effort in reviewing the contributions, improving them in the process.

\section{Notes}

1. Richard Maltby, "On the Prospect of Writing Cinema History from Below," Tijdschrift voor Mediageschiedenis 9, no. 2 (2006): 74-96, https://doi.org/10.18146/tmg.550. Also see the contribution by Jeff Klenotic in this special issue on the use of the term 'spirit'.

2. Maltby, “On the Prospect," 91, our emphasis.

3. Stefan Berger, 'Comparative History,” in Writing History. Theory and Practice, ed. Heiko Feldner and Kevin Passmore, 2nd edition (Bloomsbury Academic, 2010), 187-205.

4. Daniel Biltereyst and Philippe Meers, "New Cinema History and the Comparative Mode: Reflections on Comparing Historical Cinema Cultures," Alphaville 11 (2016): 13-32.

5. See: Kathryn H. Fuller, At the Picture Show: Small-town Audiences and the Creation of Movie Fan Culture. (Washington, DC: Smithsonian Inst Press, 1996). Robert C. Allen, “Race, Region, and Rusticity: Relocating U.S. Film History," in Going to the Movies: Hollywood and the Social Experience of Cinema, ed. Richard Maltby, Melvyn Stokes and Robert C. Allen (Exeter UK: University of Exeter Press, 2007), 25-45; Gregory A. Waller, “Imagining and Promoting the Small-Town Theater," Cinema Journal 44, no. 3 (2005): 3-19; Jeffery Klenotic, "From Mom-and-Pop to Paramount Publix: Selling the Community on the Benefits of National Theatre Chains," in Watching films: New Perspectives on Movie-going, Exhibition and Reception, ed. Karina Aveyard and Albert Moran, 189-209 (Bristol, UK: Intellect, 2013); Judith Thissen and Clemens Zimmermann, eds., Cinema Beyond the City. Bloomsbury Publishing, 2017; Philippe Meers, Daniel Biltereyst and Lies Van De Vijver, “Metropolitan vs Rural Cinema Going in Flanders, 1925-75," Screen 51, no. 3 (2010): 272-280; Daniela Treveri Gennari, Danielle Hipkins Catherine O’Rawe, eds., Rural Cinema Exhibition and Audiences in a Global Context (London, UK: Palgrave Macmillan, 2018). 


\section{Biographies}

Thunnis van Oort is a media historian. He works as a post-doctoral researcher at the CREATE digital humanities research programme of the University of Amsterdam. He has taught at universities in Utrecht and Amsterdam, coordinated the Theatre and Media Studies track at Roosevelt University College, and visited Antwerp University as a Marie Curie Pegasus research fellow in 2015, as well as participating in the AHRC-funded project 'European Cinema Audiences' coordinated at Oxford Brookes University. He is managing editor of TMG Journal for Media History.

Jessica Leonora Whitehead is a Faculty Liaison providing pedagogical support at the University of Toronto in the Faculty of Arts \& Science. Her research focuses on screen cultures in North America, and her work has appeared in the Canadian Journal of Film Studies, Transformative Works and Cultures, Italian Canadiana, and chapters in the books Rural Cinema-going from a Global Perspective and Mapping Movie Magazines. She is currently working on a book project exploring Italian-Canadian cinema cultures for McGill-Queen's Press.

TMG Journal for Media History

Volume 23 No $(1 / 2) / 2020$

DOI

https://dx.doi.org/10.18146/tmg.797

PUBLISHER

Netherlands Institute for Sound and Vision

\section{COPYRIGHT}

Each article is copyrighted (c) by its author(s) and is published under license from the author(s). When a paper is accepted for publication, authors will be requested to agree with the Creative Commons Attribution 4.0 International License. 